\title{
Saturated electricity power analysis based on Logistic curve model
}

\author{
Huiru Zhao", Sen Guo, ${ }^{1}$, Jia Zhou ${ }^{1}$, Huijuan Huo ${ }^{1}$, Wanlei Xue ${ }^{2}$ \\ ${ }^{1}$ School of Economics and Management, North China Electric Power University, Beijing, 102206, China \\ ${ }^{2}$ State Grid Shandong Electric Power Company, Power Economy \& Technology Research Institute, Jinan City, Shandong Province, \\ 250002, China
}

Email address:

guosen324@163.com (S. Guo)

\section{To cite this article:}

Huiru Zhao, Sen Guo, Jia Zhou, Huijuan Huo, Wanlei Xue. Saturated Electricity Power Analysis Based on Logistic Curve Model. International Journal of Energy and Power Engineering. Special Issue: Energy Conservation and Management.

Vol. 3, No. 6-1, 2014, pp. 1-5. doi: 10.11648/j.ijepe.s.2014030601.11

\begin{abstract}
Power load forecasting is the foundation of urban power grid planning, and saturated electricity power is a key indicator for determining the ultimate power grid scale when performing the urban power grid planning. Taken Hubei province as the empirical example, the saturated electricity power is studied by employing Logistic curve model in this paper. Firstly, the electricity power consumption and annual maximum power load of Hubei province are forecasted; then, the saturated time and scale are determined according to the judgment criteria of electricity power saturation. The calculation result shows the electricity power of Hubei province will reach saturation at 2042-2043, and the electricity power consumption and annual maximum power load will reach to 377.89 billion $\mathrm{kWh}$ and 66.2499 million $\mathrm{kW}$, respectively.
\end{abstract}

Keywords: Saturated Power Load, Logistic Curve Model, Forecasting, Hubei Province

\section{Introduction}

The analysis and prediction on urban saturated power load are helpful to coordinate the urban power grid construction and economic social development, which can also promote the sustainable development of a province or city. Saturated electricity power refers to the power scale when the electricity demand approaches the saturation phase. Urban saturated electricity power is a key indicator used for determining the ultimate scale of a province or city power grid development. Researching on the saturated electricity power can not only provide some guidance for the electric power industry development planning, especially the construction and renovation of power grid, but also promote the sustainable development of regional economy, environment and resources.

Until now, several researchers have conducted the research on urban saturated electricity power. Ref. [1] summarized the city economic and social characteristics at the stage of load saturation and also analyzed the main influencing factors of the load saturation, then the macro and micro approaches to forecast the saturated load were proposed. Ref. [2] employed the space-based saturated power load density method to analyze the urban saturated load forecasting of Fujian province, and then the saturation load density of all district function block construction area was calculated. Ref. [3] set up the saturation load forecast model by combining the methods of system dynamics and econometrics, and a case study was carried on according to the situation in Beijing, and the results showed that Beijing economy would reach saturation in 2036 and its load would reach saturation in 2038. Ref. [4] employed the ant colony algorithm and cellular automata theory to forecast the urban load saturation, and the characteristic of saturation density under different land nature was analyzed by using $\mathrm{S}$ curve model. Ref. [5] applied system dynamics principles and the VENSIM tool to forecast the saturated situation of Fuzhou city's economic curve based on the improved neoclassical economic growth theory. Ref. [6] applied the per-person electricity consumption method in saturation load forecasting, and the empirical example verified this method is effective. To estimate maximum load utilization hours, Ref. [7] proposed a new method based on per capita electricity load for saturated electricity power issue, and the saturated load of that East China city was calculated by employing logistic curve fitting. 
In this paper, we analyze the saturated electricity power by employing Logistic curve model. Taken Hubei province as the example, the power consumption and annual maximum power load are forecasted by employing Logistic curve model, and then the saturated power consumption and power load are studied.

\section{The Basic Theory of Logistic Curve Model}

Logistic curve model is a kind of Growth curve model, which was first used to predict population growth, and then was widely used in the fields of growth, development and reproduction of flora and fauna, socio-economic issues and so on [8-9]. The characteristics of Logistic curve model are as follows: in the beginning, the object grows slowly; when reach a certain period, the object grows with a rapid speed; after the object reaches a limit value, its growth rate becomes slow again. This characteristic is in common with that of power load [10]. Therefore, the Logistic curve model can be used for saturated electricity power analysis.

The mathematical expression of Logistic curve model is

$$
y=\frac{k}{1+a e^{-b t}}
$$

Where $\mathrm{k}, \mathrm{a}, \mathrm{b}$ are constants, and $\mathrm{k}>0, \mathrm{a}>0, \mathrm{~b}>0$. The Logistic curve shape is shown in Fig. 1.

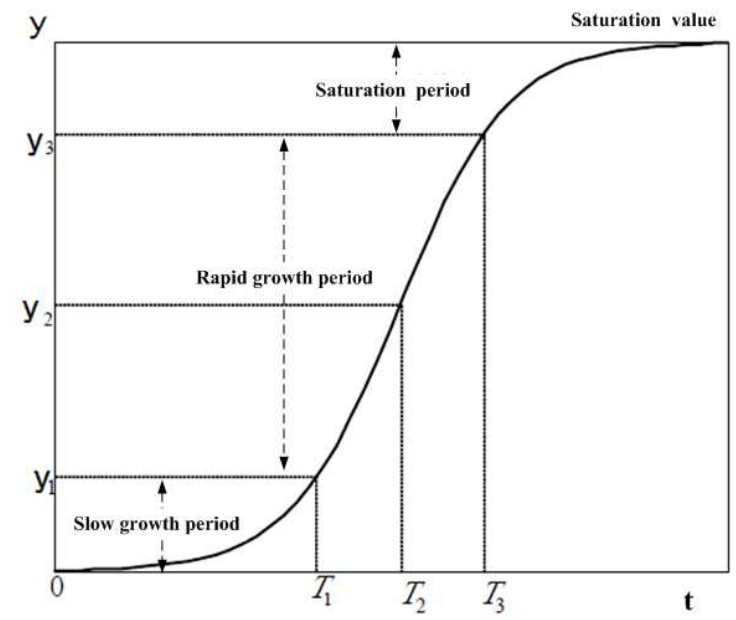

Figure 1. Logistic curve shape.

According to Eq. (1), the first-order derivative value of Logistic curve equation at any point is always positive. At the point $\left(\mathrm{T}_{2}, \mathrm{y}_{2}\right)$, the second-order derivative value equals to 0 , and at the point $\left(\mathrm{T}_{1}, \mathrm{y}_{1}\right)$ and $\left(\mathrm{T}_{3}, \mathrm{y}_{3}\right)$, the third-order derivative value equals to 0 . For Logistic curve, just as shown in Fig.1, when $\mathrm{t}$ is in the interval $\left[0, \mathrm{~T}_{1}\right], \mathrm{y}$ is at the initial slow growth stage; when $t$ is in the interval $\left[T_{1}, T_{3}\right]$, $\mathrm{y}$ is at the rapid growth stage; when $\mathrm{t}$ is in the interval $\left[\mathrm{T}_{3}\right.$, $+\infty], y$ is at the saturated growth stage; when $t$ is in the interval $\left[\mathrm{T}_{2}, \mathrm{~T}_{3}\right], \mathrm{y}$ marks a slowing in growth rate compared to that in the interval $\left[\mathrm{T}_{1}, \mathrm{~T}_{2}\right]$, and gradually becomes saturated.

When the Logistic curve model is used for electricity power forecasting, the input variables is historical electricity power data.

\section{Empirical Analysis}

In this paper, Hubei province is selected as the example, and the electricity power consumption and annual maximum power load from 1990 to 2013 are used for sample data. When employing Logistic curve model to analyze the urban saturated electricity power, the electricity power consumption and annual maximum power load of Hubei province should be fitted by Logistic model firstly; then, using the Logistic fitting curve to forecast the electricity power consumption and annual maximum power load in the future year; lastly, according to the judgment criteria of electricity power saturation, the saturated time and scale of Hubei province can be determined.

Actually, there are certain differences between electricity power consumption and annual maximum power load in a province or city. For electricity power saturation analysis, the electricity power consumption saturation and annual maximum power load saturation should be analyzed separately.

\subsection{Analysis of Electricity Power Consumption Saturation}

Firstly, the electricity power consumption of Hubei province should be fitted by using Logistic curve model. The fitting sample data is from 1990 to 2013. By using Matlab software, the Logistic curve fitting result is shown in Fig.2.

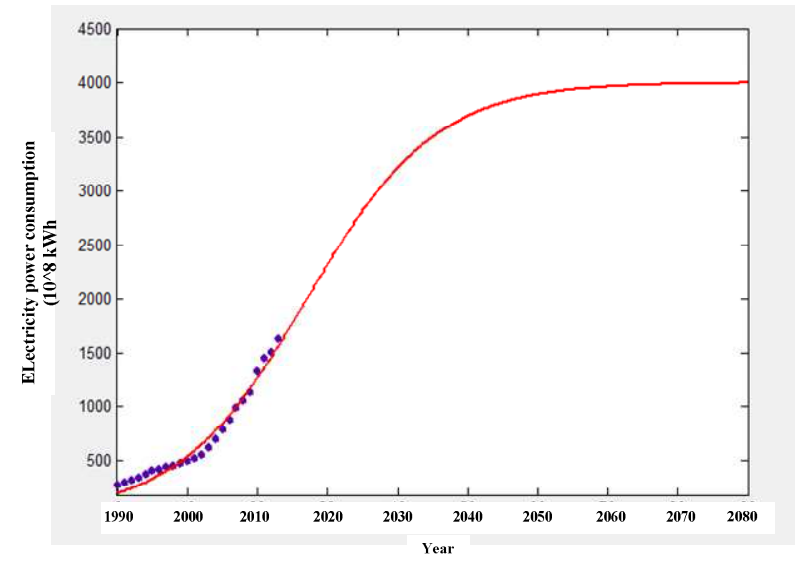

Figure 2. Fitting result of electricity power consumption of Hubei province by using Logistic curve model.

Then, the Logistic curve fitting equation can be obtained:

$$
y_{e}=\frac{4000}{1+18.99 e^{-0.1091 t}}
$$


Calculate the first-order, second-order and third-order derivative of Eq. (2), we can get $\mathrm{T}_{1}, \mathrm{~T}_{2}$ and $\mathrm{T}_{3}$, which equals to 2005,2017 and 2029 respectively. So, we can safely draw the conclusion that the electric power development of Hubei province is at the initial growth stage before 2005, and at the rapid growth stage between
2006 and 2029. After the year of 2030, the electric power development of Hubei province will step into the saturated stage.

According to Eq. (2), the electricity power consumption of Hubei province from 2015 to 2050 can be forecasted, and the result is listed in Table 1.

Table 1. Logistic forecasting result of electricity power consumption of Hubei province

\begin{tabular}{cccccc}
\hline Year & $\begin{array}{c}\text { electricity power } \\
\text { consumption (108kWh) }\end{array}$ & $\begin{array}{c}\text { annual growth } \\
\text { rate } \\
(\boldsymbol{\%})\end{array}$ & Year & $\begin{array}{c}\text { electricity power consumption } \\
(\mathbf{1 0 8 k W h )}\end{array}$ & $\begin{array}{c}\text { annual } \\
\text { growth rate } \\
(\boldsymbol{\%})\end{array}$ \\
\hline 2015 & 1784.43 & - & 2033 & 3406.49 & 1.71 \\
2016 & 1892.79 & 6.07 & 2034 & 3459.55 & 1.56 \\
2017 & 2001.79 & 5.76 & 2035 & 3508.55 & 1.42 \\
2018 & 2110.77 & 5.44 & 2036 & 3553.67 & 1.29 \\
2019 & 2219.10 & 5.13 & 2037 & 3595.14 & 1.17 \\
2020 & 2326.15 & 4.82 & 2038 & 3633.15 & 1.06 \\
2021 & 2431.31 & 4.52 & 2039 & 3667.91 & 0.96 \\
2022 & 2534.02 & 4.22 & 2040 & 3699.66 & 0.87 \\
2023 & 2633.79 & 3.94 & 2041 & 3728.60 & 0.78 \\
2024 & 2730.18 & 3.66 & 2042 & 3754.93 & 0.71 \\
2025 & 2822.80 & 3.39 & 2043 & 3778.86 & 0.64 \\
2026 & 2911.36 & 3.14 & 2044 & 3800.58 & 0.57 \\
2027 & 2995.63 & 2.89 & 2045 & 3820.26 & 0.52 \\
2028 & 3075.44 & 2.66 & 2046 & 3838.09 & 0.47 \\
2029 & 3150.71 & 2.45 & 2047 & 3854.21 & 3868.79 \\
2030 & 3221.41 & 2.24 & 2048 & 3881.95 & 3893.83 \\
2031 & 3287.55 & 2.05 & 2049 & 2050 & 0.42 \\
2032 & 3349.21 & 1.88 & & 0.38 \\
\hline
\end{tabular}

Table 2. Logistic forecasting result of annual maximum power load of Hubei province

\begin{tabular}{cccccc}
\hline Year & $\begin{array}{c}\text { electricity power } \\
\text { consumption (108kWh) }\end{array}$ & $\begin{array}{c}\text { annual growth } \\
\text { rate } \\
(\boldsymbol{\%})\end{array}$ & Year & $\begin{array}{c}\text { electricity power consumption } \\
(\mathbf{1 0 8 k W h )}\end{array}$ & $\begin{array}{c}\text { annual } \\
\text { growth rate } \\
(\boldsymbol{\%})\end{array}$ \\
\hline 2015 & 3023.73 & - & 2033 & 6026.60 & 1.72 \\
2016 & 3225.20 & 6.66 & 2034 & 6120.19 & 1.55 \\
2017 & 3428.52 & 6.30 & 2035 & 6205.97 & 1.40 \\
2018 & 3632.32 & 5.94 & 2036 & 6284.36 & 1.26 \\
2019 & 3835.23 & 5.59 & 2037 & 6355.82 & 1.14 \\
2020 & 4035.89 & 5.23 & 2038 & 6420.80 & 1.02 \\
2021 & 4233.00 & 4.88 & 2039 & 6479.76 & 0.92 \\
2022 & 4425.37 & 4.54 & 2040 & 6533.15 & 0.82 \\
2023 & 4611.91 & 4.22 & 2041 & 6581.42 & 0.74 \\
2024 & 4791.68 & 3.90 & 2042 & 6624.99 & 0.66 \\
2025 & 4963.89 & 3.59 & 2043 & 6664.25 & 0.59 \\
2026 & 5127.92 & 3.30 & 2044 & 6699.59 & 0.53 \\
2027 & 5283.30 & 3.03 & 2045 & 6731.36 & 0.47 \\
2028 & 5429.74 & 2.77 & 2046 & 6759.89 & 0.42 \\
2029 & 5567.07 & 2.53 & 2047 & 6785.48 & 6808.43 \\
2030 & 5695.28 & 2.30 & 2048 & 6828.98 & 6847.38 \\
2031 & 5814.46 & 2.09 & 2049 & 2050 & 0.38 \\
2032 & 5924.81 & 1.90 & & 0.34 \\
\hline
\end{tabular}


Table 3. Saturation analysis result of Hubei province

\begin{tabular}{llll}
\hline Item & $\begin{array}{l}\text { The year of entering saturated stage } \\
\text { (according to Criteria 1) }\end{array}$ & $\begin{array}{l}\text { The year of reaching saturation } \\
\text { (according to Criteria 2) }\end{array}$ & $\begin{array}{l}\text { Saturated scale } \\
\text { (108kWh, 104kW) }\end{array}$ \\
\hline $\begin{array}{l}\text { Electricity power } \\
\text { consumption }\end{array}$ & 2032 & 2043 & 3778.86 \\
$\begin{array}{l}\text { Annual maximum } \\
\text { power load }\end{array}$ & 2032 & 2042 & 6624.99 \\
\hline
\end{tabular}

According to Ref. [7], when the annual growth rate of a region's electricity power consumption is less than $2 \%$, we can regard the electricity demand of this region has entered the saturated stage (called Criteria 1); when the electricity power consumption reaches to the $95 \%$ of the maximum value of Logistic curve equation, we can regard the electricity power consumption has reached saturation (called Criteria 2). Therefore, we can conclude that the electricity power consumption of Hubei province will enter the saturated stage at year of 2032 and reach saturation at year of 2043. At this time, the saturated electricity power consumption of Hubei province will reach to 377.89 billion $\mathrm{kWh}$.

\subsection{Analysis of Electricity Power Load Saturation}

Firstly, the annual maximum power load of Hubei province should be fitted by using Logistic curve model. The fitting sample data is from 1990 to 2013. By using Matlab software, the Logistic curve fitting result is shown in Fig.3.

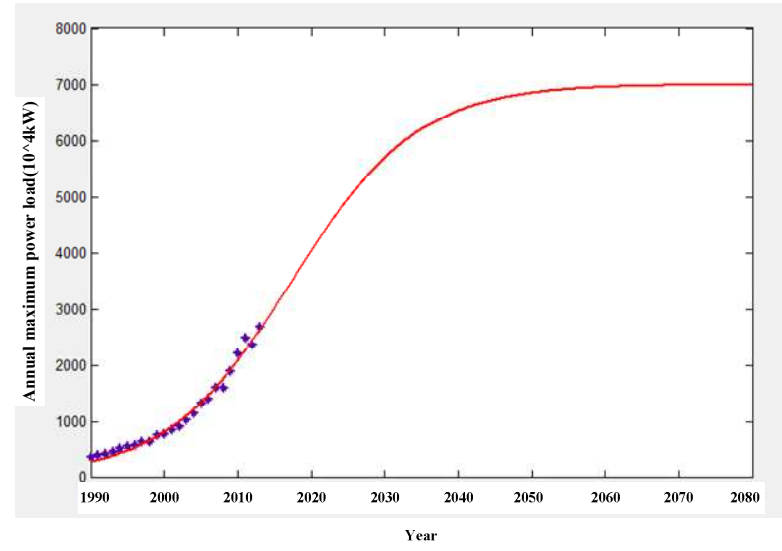

Figure 3. Fitting result of annual maximum power load of Hubei province by using Logistic curve model

Then, the Logistic curve fitting equation can be obtained:

$$
y_{p}=\frac{7000}{1+24.2 e^{-0.1165 t}}
$$

Calculate the first-order, second-order and third-order derivative of Eq. (3), we can get $\mathrm{T}_{1}, \mathrm{~T}_{2}$ and $\mathrm{T}_{3}$, which equals to 2005, 2017 and 2029 respectively. So, we can safely draw the conclusion that the electric power development of Hubei province is at the initial growth stage before 2005, and at the rapid growth stage between
2006 and 2029. After the year of 2030, the electric power development of Hubei province will step into the saturated stage. This result is consistent with that of electricity power consumption analysis.

According to Eq. (3), the annual maximum power load of Hubei province from 2015 to 2050 can be forecasted, and the result is listed in Table 2 .

According the forecasting result of annual maximum power load of Hubei province by employing Logistic curve model, we can conclude that the annual maximum power load of Hubei province will enter the saturated stage at year of 2032 and reach saturation at year of 2042. At this time, the saturated annual maximum power load of Hubei province will reach to 66.2499 million $\mathrm{kW}$.

\subsection{Comprehensive Analysis of Electricity Power Saturation}

According the forecasting results of electricity power consumption and annual maximum power load of Hubei province by using Logistic curve model, we can obtain the time and scale that electricity power reaches saturation of Hubei province, and the result is listed in Table 3.

Therefore, we can safely draw the conclusion that the electricity power of Hubei province will enter the saturated stage at the year of 2032, and reach the saturation at the year of 2042-2043. At the saturation year, the electricity power consumption and annual maximum power load will reach to 377.89 billion $\mathrm{kWh}$ and 66.2499 million $\mathrm{kW}$, respectively.

\section{Conclusions}

The analysis on urban saturated electricity power is helpful to coordinate the urban power grid construction and economic social development, which is an important topic. This paper employs Logistic curve model to study the saturated electricity power of Hubei province, China. The electricity power consumption and annual maximum power load of Hubei province are firstly forecasted by using Logistic curve model, respectively; then, according to the judgment criteria of electricity power saturation, the saturated time and scale of Hubei province are determined. The empirical analysis result shows the electricity power of Hubei province will enter the saturated stage at 2032, and reach saturation at 2042-2043. At the saturation year, the electricity power consumption and annual maximum power load of Hubei province will reach to 377.89 billion kWh and 66.2499 million $\mathrm{kW}$, respectively. 


\section{Acknowledgements}

This study is supported by Science \& Technology Program of State Grid Corporation of China.

\section{References}

[1] Cui Kai, Li Jing-ru, Zhao Biao, et al. Research on City Saturated Load and its Forecast Methods [J]. Electric Power Technologic Economics, 2008, 20(6): 34-38.

[2] Jiang Xin-qin, Li Xi-lan. City future saturated load forecasting based model of saturated load density [J]. Journal of Fuzhou University (Natural Science Edition), 2008, 36(4): $532-536$

[3] He Yongxiu, Wu Liangqi, Dai Aiying, et al. Combined saturation load forecast model based on system dynamics and econometrics [J]. Power Demand Side Management, 2010, 12(1): 21-25.

[4] Wang Jing, Feng Xian-shi, Guo Hong-zhen. Urban load saturation forecast based on ant cellular automata theory [J]. Electric Power, 2011, 44(7): 17-20.

[5] Wang Fang-dong, Lin Han, Li Chuan-dong, et al. Research on Saturated Load Macroscopically Forecast Based on Saturated Situation Analysis of Economy Curve [J]. East China Electric Power, 2010, 38(10): 1485-1490.

[6] Wang Wei, FAang Ting-ting. The application of per-person electricity consumption method in saturation load forecasting [J]. Power Demand Side Management, 2012, 14(1): 21-23.

[7] Zhang Jian-ping, Liu Jie-feng, Chen Yi-dong, et al. Saturated Load Forecasting Based on Per Capita Electricity Consumption and Per Capita Electricity Load[J]. East China Electric Power, 2014, 42(4): 661-664.

[8] Lemeshow S, Hosmer D W. A review of goodness of fit statistics for use in the development of logistic regression models [J]. American Journal of Epidemiology, 1982, 115(1): 92-106.

[9] Mood C. Logistic regression: Why we cannot do what we think we can do, and what we can do about it [J]. European Sociological Review, 2010, 26(1): 67-82.

[10] Liu Jiefeng. The Research of Saturation Load Analysis Techniques and its Application [D]. Shanghai: Shanghai Jiaotong University, 2013. 